\title{
Analysis of In-house training workshops for enhancing faculty competence in CDIO Implementation - A case study
}

\author{
Dr. S. J. Thiruvengadam ${ }^{1}$, Dr. S. Baskar ${ }^{2}$, Dr. S. Saravana Perumaal ${ }^{3}$, Dr. C. Jeyamala ${ }^{4}$, Dr. D. Anitha ${ }^{5}$, Dr. R. \\ Rajan Prakash ${ }^{6}$ \\ ${ }^{1,2}$ Professor, ${ }^{3}$ Associate Professor, ${ }^{456}$ Assistant Professor \\ Academic Process Team, Thiagarajar College of Engineering, Madurai.
}

\begin{abstract}
The CDIO INITIATIVE is an innovative educational framework that has been followed in many world-class educational institutions in USA, Europe and Asian countries for producing the next generation of engineers. It provides students with an education in the context of Conceiving — Designing - Implementing Operating (CDIO) real-world systems and products. Thiagarajar College of Engineering (TCE), Madurai is one among those institutions following the CDIO framework for all undergraduate engineering programmes since the academic year 2018-19. Though there are training programs for selective faculty members, there had been no intensive hands - on training to all the faculty members. It has been felt from the formal meetings and informal discussions that faculty members needed more clarity and training on the CDIO framework. This has led to the conduct of training workshops online by the TCE academic process team for the faculty members of the institution $(n=205)$, in three batches. Two quizzes have been conducted and feedback has been collected at the end of the workshop for each batch. This research paper analyses the outcome of these workshops measured through the Higher Order Thinking Skills (HOTS) exhibited in the assessment activities and feedback. It has been observed that the training workshop satisfies the expectations of the participants with a Satisfaction Index of 0.924 . Recommendations have been proposed for interpreting the outcomes of such training workshops to enhance faculty competence through such workshops by addressing the necessary gaps in the forthcoming training workshops.
\end{abstract}

Keywords: CDIO, Faculty Development Programs, Workshops, Assessments, Satisfaction

\section{Corresponding Author}

Dr. D. Anitha, Assistant Professor in Data Science,

Department of Applied Mathematics and Computational Science,

Thiagarajar College of Engineering, Madurai. anitha@tce.edu

\section{Introduction}

Faculty Development is a word that lingers in every mind whenever the growth of an organization is discussed. Faculty Development is essential in technical domain and pedagogical domain as well.Especially, when there is an introduction of new educational framework, there is a need of specific training programs that enables the faculty to adapt to the framework. Faculty Development is usually exercised through Faculty Development Programs (FDPs) such as short term/long term courses, training workshops and seminars. There shall be good practices in conducting any FDPsincluding the design of outcomes, measurement of outcomes, followed by the analysis of assessment and feedback (Chuchalin et al., 2016). Any Faculty Development program shall be designed with these three important elements of Outcome Based Education. Most of the programs conducted are passive in nature in the perspective of participants though with a good set of outcomes. When some programs are made interactive, the elements of assessment are found missing. Further, the faculty development programs shall be necessarily analysed for the specific needs of the participants in future programs. Literature studies have proved that effective FDPs shall lead to higher level of satisfaction and expertise (Stein et al, 2011; Konishi et al, 2020). An assurance of expertise shall be observed only from suitable assessment activities involving HOTS. Higher the performance in HOTS activities, higher the knowledge gain from the workshop.

Conceive-Design-Implement-Operate (CDIO) initiatives, a new education framework that is being followed in many world-class educational institutions, has been introduced in the institution in 2018-2019. A sequence of training programs has been conducted initially by the internal CDIO experts for selective faculty members from each department and the trained faculty members have been involved in knowledge transfer in the respective departments. There has been introduction of new courses pertaining to $\mathrm{CDIO}$ including Engineering exploration, design thinking, system thinking and lateral thinking in UG engineering programs (Thiruvengadam et al., 2020a). Though the new courses like engineering design has been well received by the students (Thiruvengadam et al., 2020b), it has been felt that CDIO initiatives needs intensive workshops to all the faculty members focusing design of CDIO curriculum, acquisition and practice of CDIO skills (Thomson \& Clark, 2018) to enhance the faculty competence in CDIO. There are some research works that have specified the need of specific faculty workshops in the components and standards of CDIO $(\mathrm{Vu}$, 
2018; Tran \&Van, 2019). There are some research works that shows the conduct of FDPs in the context of CDIO and presents the success of the program by analysing the feedback results (Chuchalin et al., 2016, Tran \& Van, 2019). However, these works have not analysed the feedback or assessments to make recommendations to the future programs. Hence, a series of CDIO training workshops has been planned with all the three elements of any FDP: Outcome based content, assessment activities to measure outcomes and analysis of feedback to find insights.

A series of workshops has been conducted with the topic "Design of CDIO curriculum" in online mode for all the faculty members $(n=205)$ in three batches in consecutive weeks. This paper consolidates the practices followed in this series of training workshops offered to the faculty in realizing a new educational framework, Conceive-DesignImplement-Operate (CDIO) in terms of outcome measurement in HOTS and analysis of feedback. The performance of faculty in HOTS level assessments would ensure the expertise that has been developed after the training and analysis of feedback gives an indication of satisfaction and identifying the future needs in such workshops. This study would be a sample study of how an FDP could be interpreted to get better insights on the outcomes.

\section{Research Questions}

This study attempts to find answers to the following Research Questions in terms of CDIO implementation in the institution.

1. How do we ensure that the participants of the workshop have got the necessary expertise in the training content?

2. How can the feedback survey be interpreted for finding satisfaction of participants and recommending changes in the future programs to enhance the faculty competence?

\section{Methods and Materials}

The workshop is conducted in online mode via google meet for 5 days of fore noon sessions with two domain experts in three batches. Google classroom has been used for content sharing, assessment and feedback survey. Initially, two major workshop outcomes have been formulated as given: At the end of the workshop the participants will be able 1) To design theory course with suitable content, delivery methods and assessment in CDIO curriculum 2) To incorporate necessary changes to be made in laboratory courses with respect to CDIO framework. Literature studies have shown that surveys and assessments are used as the major elements for finding the impact of any FDPs (Chuchalin et al., 2016; Adnan, Kalelioglu\& Gulbahar, 2017, Kim et al., 2017). Following those guidelines, two quizzes have been launched mapping these Course
Outcomes with 20 questions each, while quiz 1 has $30 \%$ of HOTS questions and quiz 2 has 55\% of HOTS questions. Figure 1 shows the snapshot of a google classroom created for one of the batches. At the end of the workshop, a feedback survey has been collected from the participants to get their views in terms of workshop content, content delivery method and assessment method as mentioned in Table 1. The responses have been collected in a Likert scale of 1 to 5 (1- Can be improved, 2- Fair, 3 - Good, 4 - Very good, 5- Excellent). Figure 2 shows the faculty participation of different designations in each of the workshops.

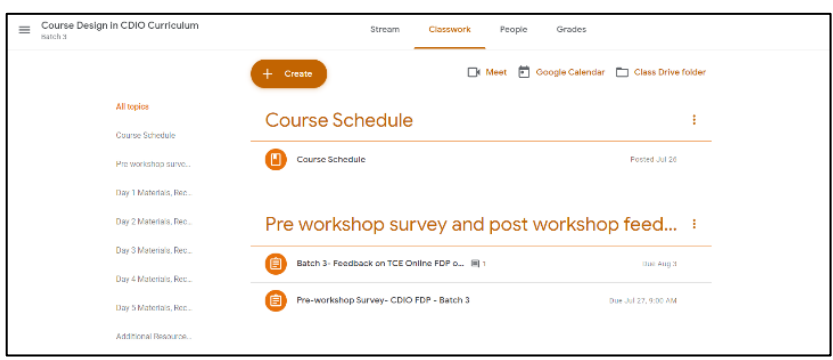

Figure 1. Snapshot of the google classroom content

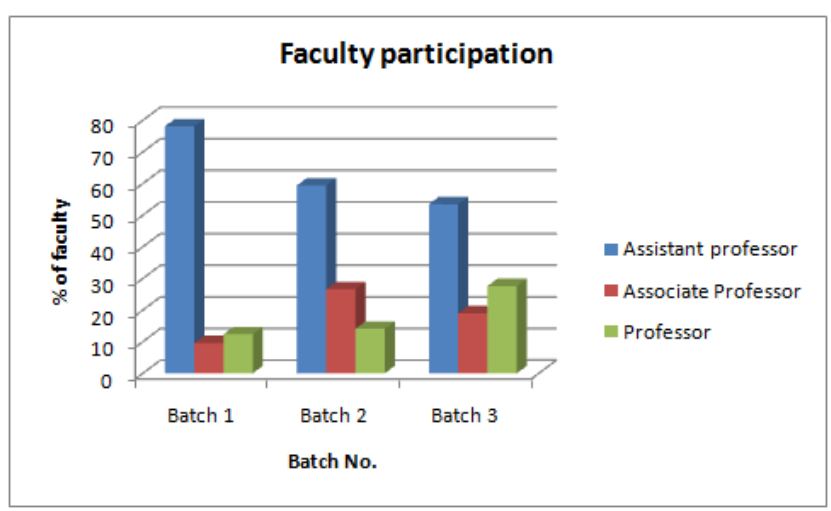

Figure 2 Participants of different designations

Table 1 Feedback Parameters

\begin{tabular}{|c|c|}
\hline & \\
\hline Parameters & Sub Parameters \\
\hline $\begin{array}{l}\text { 1.Course } \\
\text { content }\end{array}$ & $\begin{array}{l}\text { 1.1 Formulation of Course content } \\
\text { 1.2 Appropriateness of the content } \\
\text { 1.3 Content Quality } \\
\text { 1.4 Relevance of content to the course need }\end{array}$ \\
\hline $\begin{array}{l}\text { 2.Content } \\
\text { delivery }\end{array}$ & $\begin{array}{l}\text { 2.1 Depth of knowledge } \\
\text { 2.2Interactive presentation and } \\
\text { communication } \\
\text { 2.3 Response to queries }\end{array}$ \\
\hline 3. Assessment & $\begin{array}{l}\text { 3.1 Quality of assessment questions } \\
\text { 3.2 Assessment mapping with course } \\
\text { outcomes } \\
\text { 3.3 Time allotted for the assessment }\end{array}$ \\
\hline
\end{tabular}

To answer to the first research question, the performance of the faculty in the two quizzes with different composition of HOTS questions has been compared. An ANOVA test is performed to find whether the assessments results of every batch depend on the potential of the participants of the workshops. This test has been conducted to prove that the participants of three batches are equivalent in potential. The 
ANOVA test has been done with a NULL hypothesis that there is no significant difference in the quiz scores among the 3 batches. The average scores of the two quizzes are compared and a paired t-test has been performed between the faculty performance in quiz 1 and quiz 2 . This test has been conducted to find whether there is a difference between the performance in quiz as the quizzes have varying number of HOTS questions. The t-test is proposed with a NULL hypothesis that there is no significant difference between the scores of both the quizzes in each batch.

To answer to the second research question, a Satisfaction Index (SI) (Kavitha \&Anitha, 2016) is calculated using the formula

$$
S I=\sum_{i=1}^{10} \sum_{j=1}^{5} \frac{\text { Number of participants given } j \text { th scale for ith feedback parameter } X j}{\text { Total number of participants } X 5} \times 0.1
$$

where i represents the value of feedback parameters (1 to 10) as mentioned in Table 1. $\mathrm{j}$ is the weight given for the likert scale of j. For example, "Excellent" in feedback is marked as 5 in the formula (maximum value) and "Can be improved" is marked as 1 in the formula (minimum value). As we have 10 sub parameters, weight of each parameter is marked as 0.1 leading to a total weight to 1. An ANOVA test has been performed to determine if the feedback for each of the components differ for any of the batches. Similar to the previous assumption, this ANOVA test assumes a NULL hypothesis that there is no significant difference in feedback given by the faculty participated in 3 batches. This is done to find whether there exist certain elements that could differ in their perception.

Also, from the open feedback given from the faculty members, certain insights have been observed and concluded as recommendations to the future programs.

\section{Results\& Discussion}

The results and associated observations are discussed in this section. The results from ANOVA and paired t-test are tabulated in Table 2. From the ANOVA test conducted among the scores of all groups with the results as shown in the table, there is no significant difference among the three batches quiz wise as the p-values are greater than 0.05 . Hence, it shall be concluded that there is no significant difference in the potential levels of the faculty members in each batch. The average scores in both the quizzes in all the 3 batches are shown in Figure 3. From the figure, it shall be inferred that the average score of quiz 1 is higher than that of quiz 2 in all the batches. It is already mentioned that quiz 2 has 55\% HOTS questions while quiz 1 has 30\% HOTS questions. Hence from figure 3 , it shall be observed that faculty performance in Quiz 1 is higher than that of Quiz 2. Though it draws the conclusion of lesser expertise level than expected, it shall be verified through the t-test. Table 2 shows the results of paired t-test conducted between quiz 1 and quiz 2 score to find whether this difference is really significant. The resultant $p$-value as given in Table 2 has indicated that there exists significant difference in the faculty performance between quiz 1 and quiz 2 scores in all the batches. From these observations, it shall be inferred that performance of faculty in assessments containing more HOTS questions is lower than that of the performance in assessments having lesser HOTS questions. From Table 3 which shows the result of paired t-test with only HOTS questions in both the quizzes, it has been shown that there exists no significant difference between the performance of the participants in HOTS questions in both the quizzes. From these observations, it shall be concluded that the level of expertise needs to be increased in future training programs with appropriate pedagogic activities. From the open feedback given by the participants, it has been observed that the participants needed more collaborative and domain specific activities in addition to the current activities. This analysis opens the avenue of incorporating more innovative pedagogic activities in the training workshops and conducting domain specific CDIO workshops in near future.

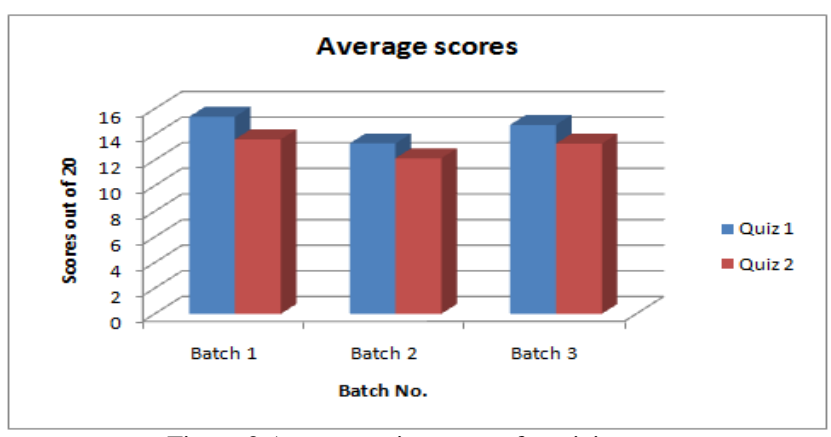

Figure 3 Average quiz scores of participants

Table 2 Paired t-test and ANOVA Results

\begin{tabular}{|l|l|l|l|}
\hline Batch & \multicolumn{2}{|l|}{ Average scores } & $\begin{array}{l}\text { Paired t-test } \\
\text { between quiz 1 } \\
\text { and quiz 2 }\end{array}$ \\
\cline { 2 - 4 } & Quiz 1 & Quiz 2 & p-value \\
\hline Batch 1 & 15.37838 & 13.61644 & 0.00001 \\
\hline Batch 2 & 13.29688 & 12.14063 & .00827 \\
\hline Batch 3 & 14.75 & 13.28788 & .00036 \\
\hline \multicolumn{3}{|l}{} \\
\hline $\begin{array}{l}\text { ANOVA test } \\
\text { for each Quiz } \\
\text { among all } \\
\text { batches }\end{array}$ & 0.0759 & 0.031806 & $\begin{array}{l}\text { Both the values > } \\
0.05\end{array}$ \\
\hline
\end{tabular}

Table 3 Paired t-test Results for HOTS Questions

\begin{tabular}{|c|c|c|c|}
\hline Batch & \multicolumn{2}{|c|}{$\begin{array}{c}\text { Average Scores for HOTS } \\
\text { question }\end{array}$} & $\begin{array}{c}\text { Paired t-test } \\
\text { between Quiz1 } \\
\text { and Quiz 2 }\end{array}$ \\
\cline { 2 - 4 } & $\begin{array}{c}\text { Quiz 1(for } \\
\text { 6 questions) }\end{array}$ & $\begin{array}{c}\text { Quiz 2 (for } \\
\text { 11 questions) }\end{array}$ & p-value \\
\hline Batch 1 & 3.45 & 5.42 & 0.0911 \\
\hline Batch 2 & 3.11 & 5.28 & 0.08 \\
\hline Batch 3 & 3.58 & 4.98 & 0.0761 \\
\hline
\end{tabular}


Next, the feedback obtained from the participants has been analysed as mentioned in Methods section. Figures 4, 5\&6 show the participant feedback in different sub parameters of the three major parameters as given in Table 1. Though it is clear from the presented figures that the training workshop has been given a very good feedback in all the parameters, an ANOVA test has been performed to determine if the feedback for each of the components differs significantly for any of the batches. The ANOVA results are tabulated in Table 4 for each sub parameter. It is evident from the pvalues obtained that there is no significant difference in the feedback given among the three batches in all the parameters and hence obvious that the workshop is satisfactory in these aspects for all the batches.

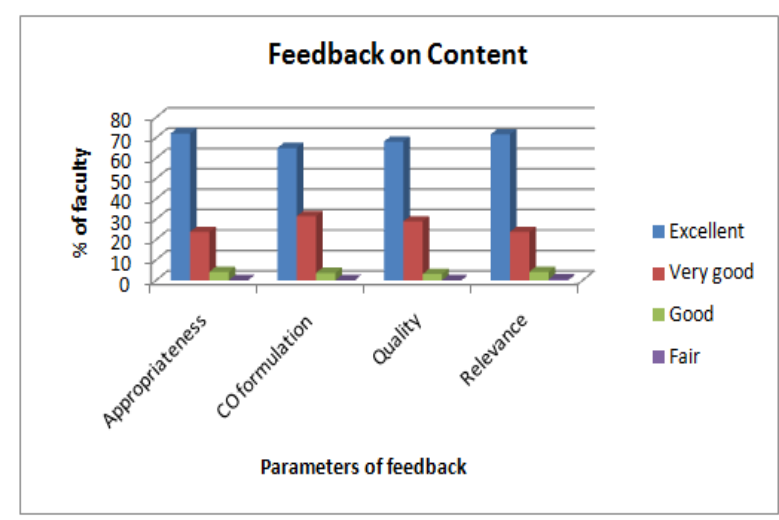

Figure 4 Participants' Feedback on Workshop Content

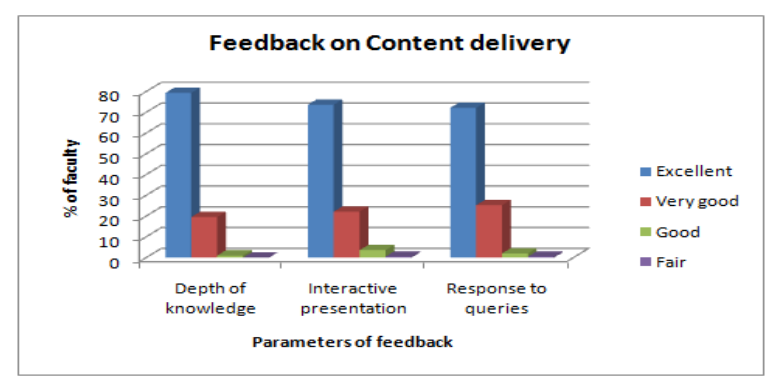

Figure 5 Participants' Feedback on Content Delivery

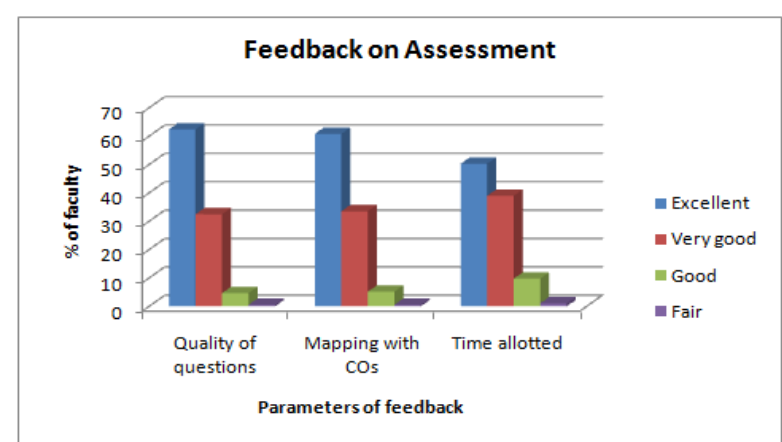

Figure 6 Participants' Feedback on Workshop Assessment
Table 4 ANOVA results on feedback

\begin{tabular}{|c|c|c|}
\hline Parameters & Sub Parameters & $\begin{array}{l}\text { ANOVA } \\
\text { p - values }\end{array}$ \\
\hline \multirow[t]{4}{*}{$\begin{array}{l}\text { 1.Course } \\
\text { Content }\end{array}$} & $\begin{array}{l}1.1 \text { Formulation of Course } \\
\text { content }\end{array}$ & 0.584712 \\
\hline & $\begin{array}{l}1.2 \text { Appropriateness of the } \\
\text { content }\end{array}$ & 0.191654 \\
\hline & 1.3 Content Quality & 0.740208 \\
\hline & $\begin{array}{l}\text { 1.4 Relevance of content to the } \\
\text { course need }\end{array}$ & 0.295093 \\
\hline \multirow{3}{*}{$\begin{array}{l}\text { 2.Content } \\
\text { Delivery }\end{array}$} & 2.1 Depth of knowledge & 0.609204 \\
\hline & $\begin{array}{l}\text { 2.2Interactive presentation and } \\
\text { communication }\end{array}$ & 0.91503 \\
\hline & 2.3 Response to queries & 0.743554 \\
\hline \multirow[t]{3}{*}{$\begin{array}{l}3 . \\
\text { Assessment }\end{array}$} & $\begin{array}{l}3.1 \text { Quality of assessment } \\
\text { questions }\end{array}$ & 0.071358 \\
\hline & $\begin{array}{l}3.2 \text { Assessment mapping with } \\
\text { course outcomes }\end{array}$ & 0.155996 \\
\hline & $\begin{array}{l}3.3 \text { Time allotted for the } \\
\text { assessment }\end{array}$ & 0.513027 \\
\hline
\end{tabular}

To analyse the feedback further, Satisfaction Index is calculated according to Equ. 1. An index of 0.924 has reached where 1 is the ideal value and hence, showing the higher satisfaction obtained from the participants. Though the performance of the participants in HOTs questions is lesser than expected, the conduct of the workshop has been appreciated by them.

Though the feedback for various elements of the program is highly satisfactory, there shall be few observations made from the feedback that may lead to future enhancement of such programs. The open-ended responses of faculty have been analysed for useful suggestions. The suggestions like "Good", "Excellent", "Nil", "No suggestions" have been discarded and count of useful suggestions are measured. Table 5 shows the correlation (Pearson Correlation coefficient) of different faculty positions participated in the 3 batches and the respective number of open-ended responses submitted. The number of open-ended responses is highly correlated with years of experience though the framework of CDIO is new to all.

Table 5. Pearson Correlation Coefficient to find Relation between Faculty Positions and Useful Responses

\begin{tabular}{|l|c|}
\hline \multicolumn{1}{|c|}{ Parameters } & $\begin{array}{c}\text { Correlation } \\
\text { Coefficient }\end{array}$ \\
\hline Assistant Professor \&open-ended responses & -0.9454 \\
\hline Associate Professor \&open-ended responses & 0.517 \\
\hline Professor \&open-ended responses & 0.929 \\
\hline
\end{tabular}

From the closed and open-ended responses of the participants through the feedback, some recommendations are inferred as mentioned in Table 6. These recommendations shall be incorporated in the future 
programs conducted for the effective implementation of $\mathrm{CDIO}$ in the institution.

Table 6. Recommendations for Future Programs

\begin{tabular}{|l|l|}
\hline \multicolumn{1}{|c|}{ Elements } & \multicolumn{1}{c|}{ Recommendations } \\
course & $\begin{array}{l}\text { Outcomes have to be devised clearly } \\
\text { More discipline specific case studies }\end{array}$ \\
\hline $\begin{array}{l}\text { Content } \\
\text { delivery }\end{array}$ & $\begin{array}{l}\text { More interactive \& Collaborative sessions are } \\
\text { to be introduced } \\
\text { There shall be specific forums to address } \\
\text { responses especially through asynchronous } \\
\text { discussions }\end{array}$ \\
\hline Assessment & $\begin{array}{l}\text { Submission deadlines for assessments shall be } \\
\text { decided based on other work constraints of the } \\
\text { faculty }\end{array}$ \\
\hline $\begin{array}{l}\text { Specific } \\
\text { guidelines }\end{array}$ & $\begin{array}{l}\text { Special programs for less experienced faculty } \\
\text { to improve their confidence in the new } \\
\text { education system } \\
\text { FDPs shall be grouped based on the needs and } \\
\text { the expertise level of the participants }\end{array}$ \\
\hline
\end{tabular}

\section{Conclusion}

This study attempts to find the mechanisms of improving the faculty competence through training workshops on a new educational framework (CDIO) introduced in the institution. Addressing faculty expertise in the training content in terms of assessment is done with quizzes. It has been found from the results of assessments that more pedagogic innovations need to be introduced in these workshops to make them excel in higher level cognitive tasks. Also, from the feedback obtained, it has been found that the participants' satisfaction is higher with a Satisfaction index of 0.924. There are few recommendations drawn from the feedback given from the participants to prepare for the next level of programs needed to improve their expertise in CDIO framework. The transformation of teachers with this training workshop in designing CDIO curriculum shall be realized in the next academic year 2021-22 as there shall be design of new courses based on CDIO initiatives. A study shall be conducted during the time to measure the outcome of this workshop in terms of student performance in CDIO courses. In future, there may be specific need-based programs based on the experience and expertise of teachers in terms of CDIO implementation. This research study paves way for looking into the organization of FDPs in the educational institutions as need based specific training workshops.

\section{References}

[1] Adnan, M., Kalelioglu, F., \& Gulbahar, Y. (2017). Assessment of a Multinational Online Faculty Development Program on Online Teaching: Reflections of Candidate E-Tutors. Turkish Online Journal of Distance Education, 18(1), 22-38.

[2] Chuchalin, A., Malmqvist, J., \& Tayurskaya, M. (2016). Professional development of Russian HEIs' management and faculty in CDIO standards application. European Journal of Engineering Education, 41(4), 426-437.

[3] Kavitha, D., and D. Anitha. "Project Based Learning Using ICT Tools to Achieve Outcomes for the Course' Microcontrollers Based System Design': A Case Study." 2016 IEEE 4th International Conference on MOOCs, Innovation and Technology in Education (MITE). IEEE, 2016.

[4] Kim, D. H., Lee, J. H., Park, J., \& Shin, J. S. (2017). Process-oriented evaluation of an international faculty development program for Asian developing countries: a qualitative study. BMC medical education, 17(1), 260.

[5] Konishi, E., Saiki, T., Kamiyama, H., Nishiya, K., Tsunekawa, K., Imafuku, R., \& Suzuki, Y. (2020). Improved cognitive apprenticeship clinical teaching after a faculty development program. Pediatrics International, 62(5), 542-548.

[6] Plavsic, S. K., \& Mulla, Z. D. (2020). The essentials of a faculty development program in the setting of a new medical school. Journal of Investigative Medicine, 68(5), 952-955.

[7] Stein, S. J., Shephard, K., \& Harris, I. (2011). Conceptions of e-learning and professional development for e-learning held by tertiary educators in New Zealand. British Journal of Educational Technology, 42(1), 145-165.

[8] Thiruvengadam, S. J., Subramanian, B., Venkatasubramani, V. R., \& Abhaikumar, V. (2020a) Design of CDIO Curriculum for Undergraduate Engineering Programme: Indian Context. In The 16th International CDIO Conference (Vol. 2, p. 65).

[9] Thiruvengadam S.J, S. Perumaal, B. Subramanian, J. Chandrasekaran, V. Abhaikumar (2020b). Design Thinking Course Implementation in CDIO Based Undergraduate Programmes. Volume 2, pp.118-132

[10] Thomson, G. A., \& Clark, R. (2018, June). Developing Staff for Effective CDIO Implementation. In The 14th International CDIO Conference in Kanazawa, Japan.

[11] Tran, N. H., \& Van Phan, N. (2019). Evaluating the CDIO-based business administration training programme using the CDIO self-evaluation rubrics at ha tinh University in Vietnam. Journal of Critical Reviews, 7(3), 2020.

[12] Vu, T. L. A. (2018). Building CDIO approach training programmes against challenges of industrial revolution 4.0 for engineering and technology development. Int. J. Eng, 11(7), 1129-1148. 